\title{
Does the Sphenoid Angle Effect the Operation Strategy? Anatomical and Radiological Investigation
}

\author{
Sfenoid Aç Cerrabi Stratejiyi Etkiler mi? Anatomik ve Radyolojik \\ Araştırma
}

Gokmen KAHILOGULLARI ${ }^{1}$, Aysun UZ², Umit EROGLU ${ }^{1}$, Nihal APAYDIN ${ }^{2}$, Zeynep YESILIRMAK ${ }^{3}$, Mustafa Kemal BASKAYA ${ }^{4}$, Nihat EGEMEN ${ }^{1}$

${ }^{1}$ Ankara University, Faculty of Medicine, Department of Neurosurgery, Ankara, Turkey

${ }^{2}$ Ankara University, Faculty of Medicine, Department of Anatomy, Ankara, Turkey

${ }^{3}$ Ankara University, Faculty of Medicine, Department of Radiology, Ankara, Turkey

${ }^{4}$ Wisconsin University, Department of Neurosurgery, Wisconsin, USA

Presented in: Turkish Neurosurgical Society, XXV. National Neurosurgical Congress, April 2010, Antalya, Turkey

Correspondence address: Gokmen KAHILOGULLARI / E-mail: gokmenkahil@hotmail.com

\begin{abstract}
AIM: The aim of our study is to suggest the sphenoid wing-lesser wing angulation (SWA) importance during surgeries directed to this region. MATERIAL and METHODS: SWA on 40 skulls were measured bilaterally $(n=80)$. The depth of the middle cranial fossa (DMCF) at the level of the SWA was determined. The same measurements were done on 40 randomly selected computerized tomography $(C T)$ scans bilaterally $(n=80)$.

RESULTS: The specimens were classified into 3 groups according the degree of SWA; Group-A, SWA was more than $130^{\circ}$ (27\%), Group-B, SWA was $110-130^{\circ}$ (43\%) and Group-C, SWA was less than $110^{\circ}$ (28\%). MCF was measured (mean) as $10.1 \mathrm{~mm}$ in Group-A, $6.4 \mathrm{~mm}$ in Group-B and $4.6 \mathrm{~mm}$ in Group-C. MCF was increasing with the increase in SWA. CT scans were classified into same procedure. Group-A was $26 \%$, Group-B was $42 \%$ and Group-C was $31 \%$ fitting in the relevant groups. The superior orbital fissure (SOF) was evaluated according to the Sharma's classification.
\end{abstract}

CONCLUSION: We suggest that by the preoperative evaluation of CT scans measurements the SWA, it is possible to estimate the MCF and the type of SOF. This knowledge may be important for all surgeries requiring removal of the sphenoid wing and these region pathologies.

KEYWORDS: Lesser wing of sphenoid bone, Superior orbital fissure, CT, Surgical approach

öz

AMAÇ: Çalışmamızın amacı sfenoid kemik-küçük kanat açısının (SWA), bu bölge cerrahi girişimlerinde önemini göstermektir.

YÖNTEM ve GEREÇLER: SWA, 40 kafatasında bilateral olarak ölçüldü $(n=80)$. Orta kranial fossanın derinliği (DMCF), SWA seviyesinde değerlendirildi. Aynı ölçüm rastgele seçilmiş hastalarda tomografi (CT) iki taraflı olarak yapıldı ( $\mathrm{n}=80)$.

BULGULAR: Örnekler SK açısının derecesine göre 3 sınıfa ayrıldı; Grup-A'da açı 130den fazla (\%27), Grup B'de açı 110-130 (\%43) ve Grup C'de açı $110^{\circ}$ den az (\%28) idi. DMCF, (ortalama) Grup-A'da 10,1 mm, Grup-B'de 6,4 mm ve Grup-C'de 4,6 mm idi. SWA artması ile DMCF'nin arttığı görüldü. CT örneklerde, kurukafalarda yapılan sınıflandırmaya göre sınıflandırıldı. Buna göre Grup-A \%26, Grup-B'de \%42 ve Grup-C'de \%31 olarak tespit edildi. Sonuçlar ile Sharma klasifikasyonuna göre superior orbital fissürün (SOF) değerlendirilmesi yapıldı.

SONUÇ: Ameliyat öncesi CT görüntülemelerinde SWA ölçümü ile DMCF değerlendirilmesinin ve SOF tipinin ortaya konulmasının mümkün olabileceğini öngörüyoruz. Bu bilgi, özellikle sfenoid kanadın alınmasının gerektiği cerrahilerinde ve bu bölge patolojilerinde önemli olacaktır.

ANAHTAR SÖZCÜKLER: Sfenoid kemik küçük kanadı, Superior orbital fissure, BT, Cerrahi yaklaşım

\section{INTRODUCTION}

Anatomical landmarks are prominent anatomical structures which provide excellent orientation to the surgeons during various kinds of surgical procedures. The neurosurgical literature also supplies substantial amount of landmarks which are approved by many authors as simple and reliable approaches determining the strategic steps of the operation $(13,20,28,31,36,37,38)$. The importance of the sphenoid bone has been emphasized in many anatomical and neurosurgical studies owing to its central position at the skull base and its significant neurovascular contents $(14,23,28,32,33,37)$. This particular bone has been the subject of much consideration with respect to the new proposals of basic $(11,12,17,21,22$, $41)$ and alternative surgical techniques $(6,9,16,25,42)$.

The sphenoid bone has a central body, paired greater and lesser wings spreading laterally from it. The superior orbital 
fissure, triangular and connecting the cranial cavity and orbit, is bounded medially by the sphenoid body, above by the lesser wing, below by the medial margin of the orbital surface of the greater wing. The posterior ridge of the lesser wing (sphenoid ridge) determines the posterior border of the anterior cranial fossa and has close relationship with the cranial nerves (III, IV, $\mathrm{VI}$, frontal and nasociliary nerve) running beneath it and with some vascular structures (superior ophthalmic vein, orbital branch of the middle meningeal artery). The lesser wing is connected to the body by an anterior root, thin and flat, and a posterior, thick and triangular root; between them the optic canal contains the optic nerve and ophthalmic artery $(37,40)$.

The CT and 3D-CT scan procedures are routinely used in surgical operations in conjugation with anatomical studies $(2,5)$. Despite the importance of the sphenoid bone that has been well reported, the importance of the angulation of the sphenoid wing has not been emphasized in previous anatomical or radiological studies. Our previous experiences made us think that the knowledge of the sphenoid angle may be of use to determine the depth of the anterior cranial fossa anteriorly, in other words to say, the posterior extension of the sphenoid wing. We also hypothesized that the degree of the sphenoid angle may contribute to the shape of the superior orbital fissure. The aim of this study, therefore, is to show how the preoperative measurement of this angulation on CT scans contributes the determination of the surgical strategy.

\section{MATERIAL and METHODS}

A three-phase approach was used for this study.

First, measurements of dry skulls were done. Forty dry human available in skull collection of the Department of Anatomy, Ankara University Faculty of Medicine were examined bilaterally $(n=80)$. The calvaria were cut horizontally in parallel to the line intersecting the lambdoid and sagittal sutures. The measurements done bilaterally and included the following rank.

First, a tangential line passing through the lesser wing of the sphenoid was determined. Then, three points were defined; point "a" was referred as the intersection point of the tangential line on lesser sphenoid wing, point " $b$ " as the tip of the anterior clinoid process and point " $c$ " as the terminal point of the lateral extension of the sphenoid wing on the lateral wall of the middle cranial fossa. These points were used to determine the sphenoid angle " $\mathrm{d}$ " which is formed by union of $a-c$ and $a-b$ lines. Finally, the vertical line perpendicular to point " $a$ " was determined as line " $\mathrm{e}$ " and perpendicular that line "e", a horizontal line was drawn to the anterior pole of the middle cranial fossa. This horizontal line was referred as line " $f$ " and this line was used to determine the anterior depth of the temporal pole (Figure 1).

The second phase included the bilateral examination of the SOF on the same specimens and classifying the specimens according to the Sharma Classification (Figure 2A,B) (32). We also determined the correlation between the degree of sphenoid angle and the Sharma Group in which the specimens fit in.

The final phase of the study included bilateral examination of the cranial 3D-CT scans. Randomly selected 3D-CT images of 40 patients were evaluated bilaterally $(n=80)$, retrospectively. The patients were informed that their scans would be used for measurements in this study. The same measurements were obtained on the CT images (Figure 3A-C).

All the measurements obtained from dry skulls were compared within groups and relation between these structures examined (Figure 4A-C).

\section{RESULTS}

We have classified our specimens into 3 groups according the degree of sphenoid wing angulation (d). According to this classification, Group A is determined as specimens possessing more than $130^{\circ}$ of angulation, Group B: specimens possessing $110-130^{\circ}$ of angulation and Group C: specimens possessing less than $110^{\circ}$ of angulation. The measurements revealed that 22 (10 left, 12 right sides) out of 80 sides (27.5\%) fit in Group A, 35 specimens (43.5\%) (17 left, 18 right sides) it in Group B and 23 specimens (28.7\%) (13 left, 10 right sides) fit in Group C (Table I) (Figure 3A-C).

The depth of the middle cranial fossa (f) was measured at a mean of $10.3 \mathrm{~mm}$ on the left sides, $9.9 \mathrm{~mm}$ on right sides of the specimens in Group A. The overall depth in Group A was calculated as $10.1 \mathrm{~mm}$ (mean). This depth was measured at a mean of $6.6 \mathrm{~mm}$ on the left sides and $6.2 \mathrm{~mm}$ on the right sides of the Group B specimens. The group mean was $6.4 \mathrm{~mm}$. And for the Group C the depth of the middle cranial fossa was measured at a mean of $4.8 \mathrm{~mm}$ on left and $4.4 \mathrm{~mm}$ on right sides with a group mean of $4.6 \mathrm{~mm}$ (Table I).

The overall sphenoid wing angulation was 119 degrees on left sides and the 118 degrees on right sides of dry bone specimens. The mean depth of the middle cranial fossa was measured as $6.9 \mathrm{~mm}$ on left and $6.8 \mathrm{~mm}$ on right sides.

The SOF on the dry bones were evaluated according to the Sharma Classification. Based on this classification our Group A specimens had 10 "Type 8", 5 "Type 7", 5 "Type 9" and 2 "Type 1" SOF. Group B possessed 16 "Type 6", 8 "Type 3", 4 "Type 1", 3 "Type 2", 3 "Type 4" and 1 "Type 8" specimens. And for the Group C numbers were as follows: 5 "Type 6", 5 "Type 7", 5 "Type 8", 2"Type 1", 2"Type 1", 2“Type 3", 2"Type 4" and 2“Type 9" (Table II) (Figure 2A-B).

The evaluation of the sphenoid wing angulation in CT and 3DCT revealed following results based on the same classification system used for dry bones. The angulation degrees between dry bones and CT- 3D CT specimens were similar:

Group A: 21 specimens (11 left, 10 right sides) (26.2\%);

Group B: 34 specimens (17 left, 17 right sides) (42.5\%);

Group C: 25 specimens (12 left, 13 right sides) (31.2\%) (Table I) (Figure 4A-C). 
The overall sphenoid wing angulation was 116.5 degrees on left and the 114.9 degrees on right sides of specimens evaluated by cranial CT. No statistical significant difference was observed on right and left sides of the specimens within same groups ( $p>0,05)$.

\section{DISCUSSION}

There is scant information in the literature regarding the angulation of the sphenoid wing. But some of the authors have pointed the importance of the angulation pattern. Venes and

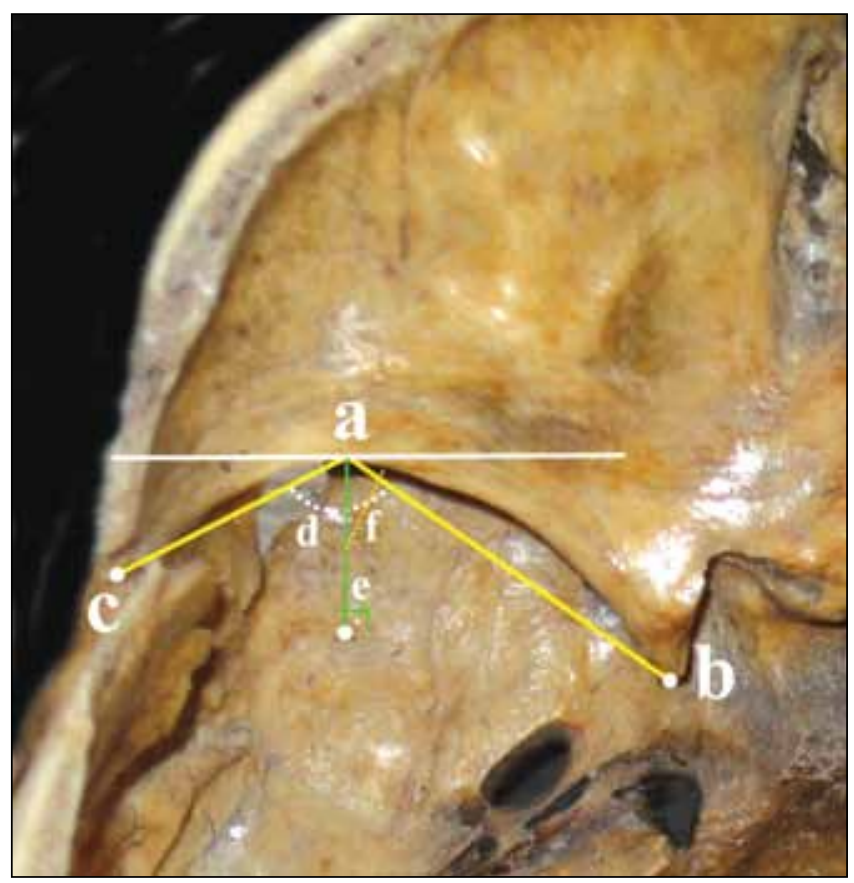

Figure 1: The angulation of the sphenoid wing (left side). a:The intersection point of the tangential line on lesser sphenoid wing. b: Tip of the anterior clinoid process. c: The terminal point of the lateral extension of the spheoid wing on the lateral wall of the middle cranial fossa. d: Sphenoid angle (which is formed by union of $a-c$ and $a-b$ lines). e: The vertical line perpendicular from point "a" to base of middle cranial fossa. $f$ : The horizontal line from middle of the 'e' point to the anterior pole of the middle cranial fossa.
Burdi has revealed that the lesser wing is showing an almost perpendicular angle in Alpert's Syndrome and postulated that the partial resection of its lateral part can fix the coronal synostosis seen is this syndrome (39). The sphenoid wing also shows some significant changes secondary to some pathological conditions (18). Ozturk et al. had revealed the angle between the sphenoid ridge and sagittal plane as 42 degrees at right and 40 degrees at left sides. And they calculated the distance between the SOF and anterior clinoid process and the alar crest (26). According to the results of the present study, we noticed that the angulations measured on dry specimens and cranial CT sections were very similar. Increase in sphenoid wing angle is significantly related with the increase in the depth of the middle cranial fossa, in other words the increase in the protrusion of the sphenoid ridge. All this knowledge made us think that the cranial bone window cranial CT scans may help the neurosurgeons to obtain information about sphenoid ridge and sphenoid wing angle. This information could be of help to plan the surgical strategy.

One of the most common used approach for intracranial pathologies is frontotemporal craniotomy or as pterional craniotomy as modified by Yasargil $(17,21,41)$. It is easy to reach a broader area if additional maneuvers are applied. With these modified approaches it is possible to access the vascular structure such as anterior circulation and basilar artery aneurysms, orbital, retroorbital, sellar, chiasmatic, retroclival and prepontine areas. Maneuvers such as changing the position of the head, retraction of the laterobasal or temporal lobes as well as removal of some bony structures from skull base provides to master these regions $(34,41)$. Removal of the inner part of the lesser wing forming the part of the orbital roof and the diploic part of the sphenoid bone has been reported to be appropriate for certain approaches. However, a careless maneuver may result in penetrating into the orbit or to the cavernous sinus $(12,41)$. The removal of the outer side of the lesser wing through the SOF was reported to increase the exposure like $1.5 \mathrm{~cm}$ (21). When the bony flap removed during pterional craniotomies, the bleeding usually results from the sphenoid wing and the middle meningeal artery (7). The sphenoid wing is suggested to be drilled through the apex of the SOF till the level of meningoorbital (recurrent meningeal)

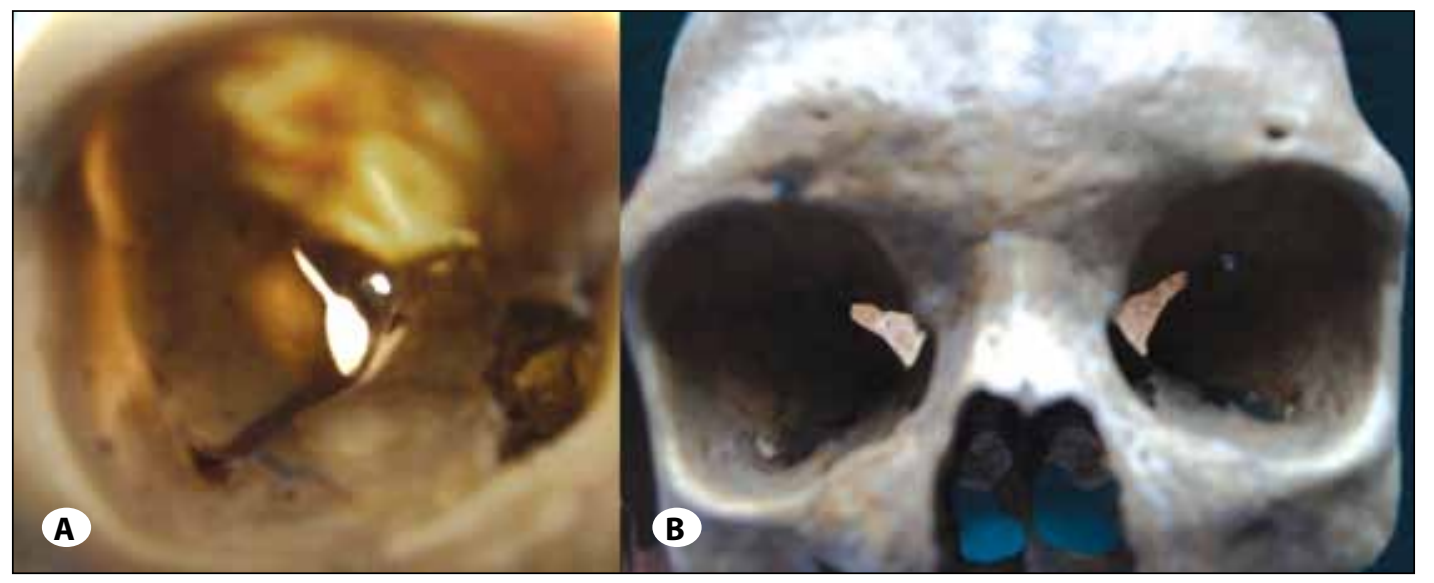

Figure 2: Superior orbital fissure samples. A) Sharma Type 8 SOF on the right orbita. Sample to'narrow type'SOF. B) Sharma Type 6 on the bilateral orbita. Sample to 'wide type' SOF. 


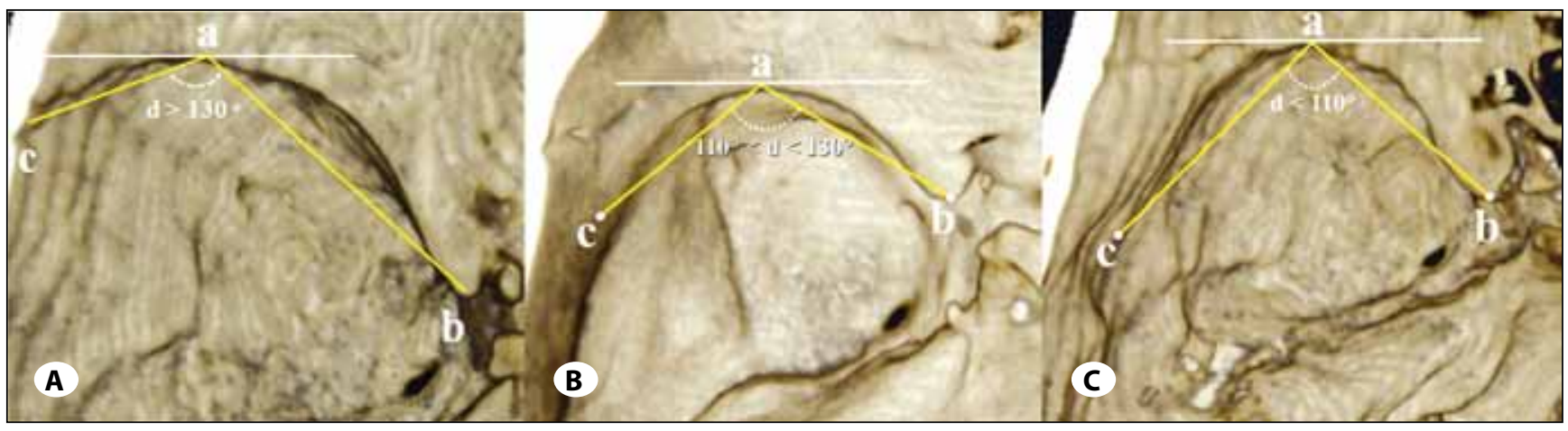

Figure 3: The type of sphenoid wing on the 3D-CT samples. A) Group A is determined as specimens possessing more than $130^{\circ}$ of angulation (left side) B) Group B specimens possessing $110-130^{\circ}$ of angulation (left side) C) Group C specimens possessing less than $110^{\circ}$ of angulation (left side).

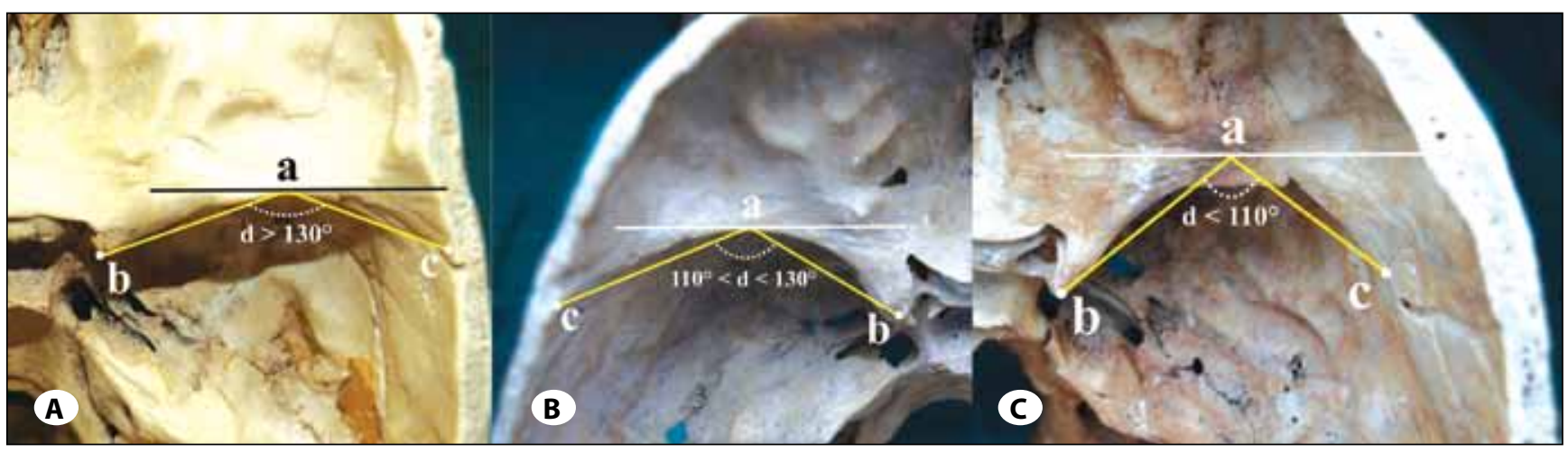

Figure 4: The type of sphenoid wing on the dry skulls samples. A) Group A is determined as specimens possessing more than $130^{\circ}$ of angulation (right side) B) Group B specimens possessing $110-130^{\circ}$ of angulation (left side) C) Group C specimens possessing less than $110^{\circ}$ of angulation (right side).

Table I: The Number and \% of the Specimens Fitting in Groups Classified According to the Sphenoid Wing Angle and the Relation Between the Depth of the Middle Cranial Fossa on Dry Skulls and the Groups

\begin{tabular}{|l|r|r|r|}
\hline & Group A & Group B & Group C \\
\hline Dry skull $(n=80)$ & $22(27 \%)$ & $35(43 \%)$ & $23(28 \%)$ \\
\hline Depth of the middle cranial fossa on dry skulls (mean) & $10.1 \mathrm{~mm}$ & $6.4 \mathrm{~mm}$ & $4.6 \mathrm{~mm}$ \\
\hline CT $(\mathrm{n}=80)$ & $21(26 \%)$ & $34(42 \%)$ & $25(31 \%)$
\end{tabular}

Table II: The SOF Types According to the Sharma Classification and their Distribution Among Groups Divided According to Degree of the Sphenoid Wing Angle (*the Medial Part of SOF is Narrower than the Other Types)

\begin{tabular}{|c|c|c|c|c|}
\hline & Group A & Group B & Group C & Number of cases and percentage \\
\hline Type 1 & 2 & 4 & 2 & $8(10 \%)$ \\
\hline Type 2 & - & 3 & - & $3(3.75 \%)$ \\
\hline Type 3 & - & 8 & 2 & $10(12.5 \%)$ \\
\hline Type 4 & - & 3 & 2 & $5(6.25 \%)$ \\
\hline Type 5 & - & - & - & $0(0 \%)$ \\
\hline Type 6 & - & 16 & 5 & $21(26.25 \%)$ \\
\hline Type $7^{*}$ & 5 & - & 5 & $10(12.5 \%)$ \\
\hline Type $8^{*}$ & 10 & 1 & 5 & $16(20 \%)$ \\
\hline Type $9 *$ & 5 & - & 2 & $7(8.75 \%)$ \\
\hline Total & 22 & 35 & 23 & 80 \\
\hline
\end{tabular}


artery and thus an attempt made to obtain greater exposure $(1,8,11,41)$. Rhoton has emphasized that removal of the part of lesser wing which is close to the orbital roof and the roof of the optic canal as well as the sphenoid ridge makes it possible to access a wide area such as the anterior circulation and the basilar artery aneurysms (30). Similarly, removal of the greater wing of the sphenoid and the squamous portion of the temporal bone was reported to increase the mobility of the anterior temporal lobe (41). The maximal excision line was suggested as $6 \mathrm{~cm}$ from the tip of the temporal tip for the left side and $7-8 \mathrm{~cm}$ for the right side (22). All these information and data show us that any preoperative assessment of the sphenoid wing anatomy is very important for neurosurgeons.

According to our observations we considered that the shape of the SOF can be evaluated based on sphenoid wing angle. Sharma et al. has classified the shape of SOF into 9 distinct types (32). They reported that the SOF gets narrower on the medial side especially in Type 7, 8 and 9. In the present study we observed that the differences in the angulation of the sphenoid wing may effect the shape of the SOF (Table 2). Accordingly, the specimens possessing Group A pattern sphenoid wing had a narrow SOF as specified in "narrow type" SOF. However in Group B, only one specimen had a narrow SOF. In Group C (narrow angle sphenoid wing), the number of the specimens possessing narrow (Type 7-9) and wide (Type 1-6) SOF were almost equal. Based on these results, we suggest that the shape of the SOF can be evaluated with preoperative cranial CT and thus planning of the surgical strategy becomes easy. The pterional approach directed to SOF necessitates removal of the sphenoid wing so that precise information of the related area is mandatory $(3,23,33)$. Coscarella et al. had offered an alternative extradural exposure to the anterior clinoid process via the SOF as a surgical corridor which proved easier and more reliable surgery in every case. Based on all this information, it may be postulated that the preoperative evaluation of the SOF anatomy increases the surgical success (9).

One of the pathologies regarding this region is meningiomas of the sphenoid wing. It has been reported as one of the most common type of meningioma together with parasagittal meningiomas (4). Brotchi and Bonnal has classified these kinds of meningiomas under 5 groups. Accordingly, Group A: deep or clinoidal or sphenocavernous, Group B: en plaque of the sphenoid wings, Group C: en masse of the sphenoid wings (Group A+ Group B), Group D: Middle ridge tumor, Group E: Pterional global tumor or sylvian point tumor. Of these, the groups of meningiomas related to our study can be considered as Group B and D.

In case of a pathology related to one of the sphenoid wings, data gathered from preoperative $\mathrm{CT}$ evaluation of the normal side of the sphenoid wing may be used to make assessments of the sphenoid wing angle, depth of the middle cranial fossa and the shape of the SOF of the pathologic side. Thus the surgical strategy can be determined. In those cases, appropriate removal of the sphenoid wing may increase the surgical success. Even if a large bony segment is removed, there will be no need to make a bony reconstruction soon (4). Whatever the type of the sphenoid wing meningioma, the authors invariably report the trick of the surgical technique as removal of the sphenoid wing after providing a good anatomical orientation for SOF and the related area $(10,15$, 19, 24, 27).

\section{CONCLUSIONS}

1. The measurements obtained from dry skulls and the CT and/or 3D-CT scans are almost identical and the proposed classification is valid for both groups.

2. Increase in sphenoid wing angle is significantly related with the increase in the protrusion of the sphenoid wing.

3. The medial part of the SOF is quite narrow among the group with the widest sphenoid angle. The SOF is not narrow at all among the group with the medium angle wideness. However, the size of the SOF may vary among the group with the narrowest wing angle.

A detailed knowledge of sphenoid ridge and SOF is mandatory both for preoperative planning of surgical strategies and to lower the risk of iatrogenic injury during neurosurgical approaches. We suggest that the results of the present study serves substantial data to the neurosurgeons for the determination of sphenoidal angle and SOF anatomy on routine preoperative CT and especially on 3D-CT scans, so that contributes the determination of the surgical strategy before the operation.

\section{REFERENCES}

1. Abdel Aziz KM, Chiocoine MR, van Loveren HR: Surgical corridors to the skull base, in Batjer $\mathrm{HH}$, Loftus CM, (eds), Textbook of Neurological Surgery. Philadelphia: Lippincott Williams and Wilkins, 2003: 29-44

2. Alvernia JE, Spomar DG, Olivero WC: A computed tomography scan and anatomical cadaveric study of the pterygopalatine ganglion for use in Gamma-Knife treatment of cluster headache. J Neurosurg 107: 805-808, 2007

3. Ammirati $M$, Bernardo A: Anatomical study of the superior orbital fissure as seen during a pterional approach. J Neurosurg 106:151-156, 2007

4. Brotchi J, Bonnal JP: Lateral and middle sphenoid wing meningiomas, in Al-Mefty O, (eds), Meningiomas. Newyork: Raven Press, 1991: 413-425

5. Bulsara KR, Leveque JC, Gray L, Fukushima T, Friedman $A H$, Villavicencio AT: Three-dimensional computed-tomographic analysis of the relationship between the arcuate eminence and the superior semicircular canal. Neurosurgery 59:7-12, 2006

6. Collignon F, Link M: Paraclinoid and cavernous sinus regions: Measurement of critical structures relevant for surgical procedure. Clin Anat 18: 3-9, 2005

7. Connolly ES, McKhann GM, Huang J: Fundamentals of operative techniques in neurosurgery. Major cranial approachesPterional approaches. Newyork-Stuttgart: Thieme, 1994: 202209 
8. Connolly ES, McKhann GM, Huang J: Fundamentals of operative techniques in neurosurgery. Major cranial approaches-Dolenc approach. Newyork-Stuttgart: Thieme, 1994: 268-275

9. Coscarella E, Baskaya MK, Morcos JJ: An alternative extradural exposure to the anterior clinoid process: The superior orbital fissure as a surgical corridor. Neurosurgery 53:162-167, 2003

10. Cui H, Wang Y, Yin Y, Wan J, Fei Z, Gao W, Jiang J: Surgical management of anterior clinoidal meningiomas: A 26-case report. Surg Neurol 68: 6-10, 2007

11. Day AL, Cawley CM: Surgical managements of aneurysms and fistulas involving the cavernous sinus, in Schmidek A, Sweet WH, (eds), Operative Neurosurgical Techniques. Philadelphia: WB Saunders Company, 2000: 341-350

12. Dolenc VV: Approaches to and techniques of surgery within the cavernous sinus, in Torrens M, Al-Mefty O, Kobayashi S, (eds), Operative Skull Base Surgery. Churchill Livingstone, 1997: 207-236

13. Ebeling U, Rikli D, Huber P, Reulen HJ: The coronal suture, a useful bony landmark in neurosurgery? Craniocerebral topography between bony landmarks on the skull and the brain. Acta Neurochir (Wien) 89:130-134, 1987

14. Govsa F, Kayalioglu G, Erturk M, Ozturk T: The superior orbital fissure and its contents. Surg Radiol Anat 21:181-185, 1999

15. Honeybul S, Neil-Dwyer G, Lang DA, Evans BT, Ellison DW: Sphenoid wing meningioma en plaque: A clinical review. Acta Neurochir (Wien) 143: 749-758, 2001

16. Huynh-Le P, Natori Y, Sasaki T: Surgical anatomy of the anterior clinoid process. J Clin Neurosci 11: 283-287, 2004

17. Inoue T, Rhoton AL Jr, Theele D, Barry ME: Surgical approaches to the cavernous sinus: A microsurgical study. Neurosurgery 26: 903-932, 1990

18. Jacquemin C, Mullaney P, Bosley TM: Abnormal development of the lesser wing of the sphenoid with microphthalmos and microcephaly. Neuroradiology 43: 178-182, 2001

19. Jesus O, Toledo MM: Surgical management of meningioma en plaque of the sphenoid ridge. Surg Neurol 55: 265-269, 2001

20. Krayenbühl N, Isolan GR, Al-Mefty O: The foramen spinosum: A landmark in middle fossa surgery. Neurosurg Rev 3: 397-402, 2008

21. Meyer FB: Atlas of Neurosurgery- Pterional approach. New York: Churchill Livingstone, 1999: 1-48

22. Meyer FB: Atlas of Neurosurgery-Frontotemporal approach. New York: Churchill Livingstone, 1999: 49-82

23. Morard M, Tcherekayev V, de Tribolet N: The superior orbital fissure: A microanatomical study. Neurosurgery 35: 1087-1093, 1994

24. Nakamura M, Roser F, Jacobs C, Vorkapic P, Samii M: Medial sphenoid wing meningiomas: Clinical outcome and recurrence rate. Neurosurgery 58:627-639, 2006

25. Otani N, Muroi C, Yano H, Khan N, Pangalu A, Yonekawa Y: Surgical management of tuberculum sellae meningioma: Role of selective extradural anterior clinoidectomy. $\mathrm{Br} \mathrm{J}$ Neurosurg 20:129-138, 2006
26. Oztürk A, Bozbuğa M, Bayraktar B, Ari Z, Sahinoglu K, Polat G, Gurel I: Surgical anatomy and morphometric analysis of the optico-chiasmatic apparatus, optic canal and sphenoid ridge. Okajimas Folia Anat Jpn 75: 319-22, 1999

27. Puzzilli F, Ruggeri A, Mastronardi L, Agrillo A, Ferrante L: Anterior clinoidal meningiomas: Report of a series of 33 patients operated on through the pterional approach. Neuro Oncol 1:188-195, 1999

28. Reis CV, Sankar T, Crusius M, Zabramski JM, DeshmukhP, Rhoton AL Jr, Spetzler RF, Preul MC: Comparative study of cranial topographic procedures: Broca's legacy toward practical brain surgery. Neurosurgery 62:294-310, 2008

29. Reymond J, Chautra A, Wysocki J: The morphology and morphometry of the foramina of the greater wing of the human sphenoid bone. Folia Morrphol (Warsz) 64:188-193, 2005

30. Rhoton AL Jr: The suptatentorial cranial space: Microsurgical anatomy and surgical approaches-Aneurysms. Neurosurgery 51:121-158, 2002

31. Ribas GC, Ribas EC, Rodrigues CJ: The anterior sylvian point and the suprasylvian operculum. Neurosurg Focus 15:E2, 2005

32. Sharma PK, Malhotra VK, Tewari SP: Variations in the shape of the superior orbital fissure. Anat Anz 165:55-56, 1988

33. Shi $X$, Han H, Zhao J, Zhou C: Microsurgical anatomy of the superior orbital fissure. Clin Anat 20:362-366, 2007

34. Takahashi JA, Kawarazaki A, Hashimoto N: Intradural en-bloc removal of the anterior clinoid process. Acta Neurochir (Wien) 146: 505-509, 2004

35. Tubbs RS, Salter EG, Oakes WJ: Superficial surgical landmarks for the transverse sinus and torcular herophili. J Neurosurg 93:279-281, 2000

36. Tubbs RS, O'Neil JT Jr, Key CD, Zarzour JG, Fulghum SB, Kim EJ, Lyerly M, Shoja MM, Salter EG, Oakes WJ: Superficial temporal artery as an external landmark for deeper-lying brain structures. Clin Anat 20:498-501, 2007

37. Tubbs RS, Salter EG, Oakes WJ: Quantitation of and measurements utilizing the sphenoid ridge. Clin Anat 20: 131-134, 2007

38. Uz A, Ugur HC, Tekdemir I: Is the asterion a reliable landmark for the lateral approach to posterior fossa? J Clin Neurosci 8:146-147, 2001

39. Venes JL, Burdi A: Proposed role of the orbital sphenoid in craniofacial dysostosis. Concepts Pediatr Neurosurg 5: 126-135, 1985

40. Williams PL: Gray's Anatomy the anatomical basis of medicine and surgery. Edinburgh: Churchill Livingstone, 1995: 587

41. Yasargil MG: Microneurosurgery. Volume I. General operative techniques-Operative approach-Interfascial pterional (frontotemporosphenoidal) craniotomy. Stuttgart-Newyork: Georg Thieme Verlag, 1984: 215-233

42. Youssef S, Kim EY, Aziz KM, Hemida S, Keller JT, van Loveren HR: The subtemporal interdural approach to dumbbellshaped trigeminal schwannomas: Cadaveric prosection. Neurosurgery 59: 270-278, 2006 